Nota

\title{
DISPONIBILIDADE DE BORO EM SUBSTRATO PARA PRODUÇÃO DE PORTA-ENXERTOS DE CITROS EM FASE DE SEMENTEIRA $\left(^{\mathbf{1}}\right)$
}

\author{
DIRCEU MATTOS JUNIOR $\left({ }^{2,6}\right)$; RODRIGO MARCELLI BOARETTO $\left({ }^{2}\right)$; EMANUEL ROBERTO \\ DE LIMA CORRRÊA $\left({ }^{4}\right)$; MÔNICA FERREIRA DE ABREU $\left({ }^{5}\right)$; SERGIO ALVES DE CARVALHO $\left({ }^{2,6}\right)$
}

\begin{abstract}
RESUMO
A produção de mudas cítricas em ambiente protegido, associada ao uso de substratos, requer estratégias adequadas de manejo no viveiro. Problemas de falta e/ou excesso de nutrientes freqüentemente causam prejuízos ao setor. Em citros ocorrem diferentes respostas à disponibilidade de boro (B) para a planta e são comuns danos causados pela toxidez desse nutriente. Este trabalho teve como objetivo avaliar os efeitos da adição de B no substrato sobre a absorção e o crescimento de duas variedades de porta-enxertos de citros em fase de sementeira. O experimento foi desenvolvido em esquema fatorial, com limão 'Cravo' e citrumelo 'Swingle' e quatro doses de B misturadas ao substrato na forma de $\mathrm{H}_{3} \mathrm{BO}_{3}\left(0,3,6\right.$, e $12 \mathrm{~g} \mathrm{~m}^{-3}$ de B), em três repetições. Avaliaram-se os teores de $B$ no substrato no início do experimento, aos 55 e 110 dias de sementeira, e o crescimento dos seedlings e a absorção de B pelas plantas nos mesmos intervalos. Os teores de B no substrato variaram entre 0,1 e 4,7 mg $\mathrm{L}^{-1}$. Aos 55 e 110 dias, houve decréscimo nos teores do nutriente nas plantas provavelmente devido às perdas do nutriente do substrato por lixiviação. Observaram-se sintomas visuais de fitotoxicidade de B nos porta-enxertos cultivados no substrato tratado com $3 \mathrm{~g} \mathrm{~m}^{-3}$ de $\mathrm{B}$, quando o teor na planta foi $>100 \mathrm{mg} \mathrm{kg}^{-1}$. O excesso de B causou redução no crescimento dos porta-enxertos. O maior crescimento e acúmulo de B na massa seca de plantas de citrumelo 'Swingle', comparado ao 'Cravo, indicam maior tolerância do primeiro à fitotoxicidade de B.
\end{abstract}

Palavras-chave: nutrição, micronutriente, viveiro, análise química, toxicidade de boro.

$\left({ }^{1}\right)$ Recebido para publicação em 17 de setembro de 2007 e aceito em 15 de setembro de 2008.

$\left({ }^{2}\right)$ Centro de Citricultura Sylvio Moreira, Instituto Agronômico, Rod. Anhanguera, km 158, 13490-970 Cordeirópolis (SP). E- mail: ddm@centrodecitricultura.br $\left(^{*}\right)$ Autor para correspondência; sergio@centrodecitricultura.br; boaretto@iac.sp.gov.br $\left({ }^{3}\right)$ Engenheiro Agrônomo, ex-bolsista IAC PIBIC/CBPq.

$\left({ }^{4}\right)$ Centro de Solos e Recursos Ambientais, Instituto Agronômico, Caixa Postal 28, 13012-970 Campinas (SP), E-mail: monica@iac.sp.gov.br

$\left({ }^{5}\right)$ Bolsista do CNPq. 


\title{
ABSTRACT \\ BORON AVAILABILITY IN THE GROWTH MEDIA FOR PRODUCTION OF CITRUS ROOTSTOCK SEEDLINGS
}

\begin{abstract}
The production of citrus nursery trees under protected environment using growth media requires healthy management practices. Problems associated with deficiency and/or nutrient excess have frequently caused economic losses in the nursery. Citrus grow differently depending on boron (B) availability in the growth media, even tough B toxicity commonly cause damage to plants. This research aimed to evaluate the effects of B supply in the growth media on nutrient uptake and seedling growth of two rootstock citrus varieties. A factorial design was set up with two factors: two rootstocks (Rangpur lime and Swingle citrumelo) and four B levels added to the substrate $\left(0,3,6, \mathrm{e} 12 \mathrm{~g} \mathrm{~m}^{-3} \mathrm{~B}\right)$ as boric acid, with 3 replications. Boron availability in the substrate was evaluated at beginning the experiment, 55 and 110 days after rootstock seeding, as well as seedling growth and B uptake by seedlings in the same time intervals. Boron concentration in the treated substrate varied from 0.1 to $4.7 \mathrm{mg} \mathrm{L}^{-1}$, whereas B concentration in the whole plant tissue decreased in both evaluation periods probably because of nutrient leaching losses from substrate. Visual symptoms of B toxicity were observed for seedlings grown in substrate with $B$ added at $3 \mathrm{~g} \mathrm{~m}^{-3}$, which were associated with $B$ concentration in the plant tissue $>100$ $\mathrm{mg} \mathrm{kg}{ }^{-1}$. Excess $B$ caused reduced growth of seedlings. The greater growth and B content in the dry mass of 'Swingle' compared to 'Cravo' rootstock plants denoted greater tolerance of the former to B toxicity.
\end{abstract}

Key words: nutrition, micronutrient, nursery, chemical analysis, boron toxicity.

\section{Introdução}

O bom desenvolvimento da citricultura depende do uso de material genético superior e de mudas de alta qualidade sanitária, que somente podem ser produzidas em ambientes protegidos, isolados de vetores de doenças como clorose variegada dos citros (CVC), cancro cítrico e huanglongbing (HLB), e em substratos livres de patógenos (i.e.: Phythophtora e nematóides), respeitando-se exigências de normas específicas (CARVAlHo, 2003). Neste sistema de produção de mudas de citros, a adoção de estratégias de manejo adequadas para otimização da produção é importante visto a necessidade do setor para a manutenção da competividade e qualidade superior do produto.

Em condições de cultivo protegido, o período de formação da muda citrica pode ser reduzido para 8 a 16 meses, enquanto em viveiros de campo eram necessários até 20 meses (CASTle e Rouse, 1990; Teófilo Sobrinho, 1991). Esse período ocorre principalmente em função de temperaturas mais altas no interior dos telados e disponibilidade de água otimizada para o crescimento vegetal. Além destes fatores, o manejo nutricional das mudas cítricas em ambientes telados com o uso de recipientes difere do antigo sistema convencional em campo, pois os substratos, possuem características físicas e químicas distintas do solo nos viveiros abertos.

Os substratos são de composição variável, com misturas de turfa, cascas e palhas vegetais, vermiculita e outros componentes (KäMPF, 2002; ZANETTI et al., 2003). A composição química do substrato é determinante para o desenvolvimento adequado dos porta-enxertos (SCHÄFER et al., 2006), influenciando diferentemente condições de desenvolvimento da copa sobre os mesmos porta-enxertos (MOURÃo FILHO, 1989). Fertilizantes minerais podem ser adicionados aos substratos, no entanto, existem dúvidas sobre doses adequadas para a produção de mudas cítricas em substrato, o que tem determinado muitas vezes desbalanços nutricionais, prejudicando o crescimento das plantas, em função da falta ou excesso de determinado elemento.

Vários autores (BERNARDI et al., 2000; CARVALHO et al., 2000; Mattos Junior et al., 2001; BoAventura et al., 2004) estudaram a adubação com macronutrientes na produção de mudas em substrato. Por outro lado, problemas envolvendo micronutrientes não têm tido a mesma abordagem.

A toxidez de boro (B) em seedlings de portaenxertos foi identificada em viveiros (MATTOS JúnIoR et al., 1995) e associada a teores de $B>5 \mathrm{mg} \mathrm{kg}^{-1}$ no substrato (extraído em água quente; ABReu et al., 1994). Ainda, no referido trabalho, o teor total de $B$ no substrato revelou baixa correlação com o B acumulado na planta.

Em viveiros, o desbalanço de B constitui um problema para algumas variedades de porta-enxertos, em decorrência da resposta característica dos citros, pois o sintoma visual da toxidez ocorre a níveis distintos de concentrações foliares do nutriente conforme a variedade (CHAPMAN, 1958). Os prejuízos devido à toxidez de $\mathrm{B}$ são relacionados ao menor crescimento do material vegetativo, com conseqüente atraso no período de formação da muda e perda da qualidade desejada. 
Desta forma, estabeleceu-se um estudo com o objetivo de avaliar o desenvolvimento de dois portaenxertos de citros produzidos em fase de sementeira em condições de ambiente protegido e identificar os níveis críticos de B no substrato para a produção adequada.

\section{Material e Métodos}

O projeto foi desenvolvido em telado localizado no Centro de Citricultura Sylvio Moreira (IAC), em Cordeirópolis, na fase de crescimento dos seedlings de citros, compreendida entre a germinação e o transplantio para recipientes plásticos rígidos, sob ambiente protegido com tela, conforme requerido pelas normas vigentes da Secretaria de Agricultura e Abastecimento do Estado de São Paulo (Carvalho, 2003). Foram avaliados dois porta-enxertos: limão 'Cravo' (Citrus limonia Osbeck) e citrumelo 'Swingle' [Poncirus trifoliata (L.) Raf. x C. paradisi Macf.]. As sementes utilizadas foram coletadas no banco de sementes do Centro de Citricultura Sylvio Moreira IAC, tratadas com fungicidas e armazenadas em câmara fria até sua utilização.

As sementes foram pré-germinadas, sem o tegumento, em bandejas plásticas perfuradas e preenchidas com substrato (Tabela 1). Nesse substrato, correspondente ao lote que não recebeu a aplicação de $\mathrm{B}$, o teor inicial de $\mathrm{B}$ foi de $0,1 \mathrm{mg} \mathrm{L}^{-1}$. Os teores médios de nutrientes em extrato saturado 1:1,5 (Sonneveld e Van Elderen, 1994), em $\mathrm{mg} \mathrm{L}^{-1}$, observados no substrato antes da adição do $\mathrm{B}$, foram: $\mathrm{N}-\left(\mathrm{NH}_{4}+\mathrm{NO}_{3}\right)=6,3, \mathrm{P}=2,5, \mathrm{~K}=135, \mathrm{Ca}=$ $133, \mathrm{Mg}=28, \mathrm{~S}=255$ e micronutrientes $(\mathrm{Cu}, \mathrm{Fe}, \mathrm{Mn}$ e Zn) $<0,1$.

Posteriormente, seedlings com cerca de dois pares de folhas formadas, foram transplantados para os recipientes plásticos cônicos (tubetes) com capacidade para $0,05 \mathrm{dm}^{3}$, preenchidos com substrato à base de composto de casca de pínus e de vermiculita (Rendimax ${ }^{\circledR}$ Eucatex, Paulínia, SP), sem a adição de micronutrientes, previamente preparado e homogeneizado com $0,3,6$, e $12 \mathrm{~g} \mathrm{~m}^{-3}$ de $\mathrm{B}$. A fonte de $\mathrm{B}$ adicionada ao substrato, foi o $\mathrm{H}_{3} \mathrm{BO}_{3}$, dissolvido em água conforme a dosagem e aspergido uniformemente ao substrato, o qual foi incubado à temperatura ambiente por 10 dias antes do transplante dos seedlings. Os tubetes foram acondicionados em bandejas com 98 células cada uma, mantidas em ambiente com cobertura de tela aluminizada e transparência de $50 \%$. A irrigação foi feita por aspersão, duas vezes por semana, utilizando sistema automático de irrigação, na taxa de $25 \mathrm{~mL}$ tubete $^{-1}$. Foi aplicada, em dois intervalos alternados à irrigação, o total de $50 \mathrm{~mL}$ tubete ${ }^{-1}$ da solução nutritiva contendo, em mg L-1, N-NO $\mathrm{NO}_{3}$ (202), N-NH $\mathrm{N}_{4}$ (15), $\mathrm{P}(16), \mathrm{K}(185), \mathrm{Ca}(150), \mathrm{Mg}(30), \mathrm{S}(20), \mathrm{Fe}(1,8)$, Mn $(0,21)$ e Zn $(0,21)$.

O experimento foi estabelecido em delineamento inteiramente casualizado em esquema fatorial $2 \times 4$ com os porta-enxertos limão 'Cravo' e citrumelo 'Swingle' e as doses de B: a em três repetições. As parcelas experimentais foram compostas por 40 plantas úteis.

Após transferência dos seedlings para os tubetes, os porta-enxertos foram cultivados por 110 dias. Amostras com 20 plantas foram colhidas aos 55 e 110 dias para avaliação da produção de massa seca de raízes e parte aérea. Após a secagem do material vegetal em estufa de circulação forçada de ar a $65^{\circ} \mathrm{C}$, foram determinados os teores de nutrientes na planta toda, conforme método descrito por BATAGLIA et al. (1983). Separaram-se 10 amostras de plantas para a determinação da densidade de comprimento de raízes $\left(\mathrm{Lv} ; \mathrm{cm} \mathrm{cm}^{-3}\right)$ e área foliar $\left(\mathrm{AF} ; \mathrm{cm}^{2}\right)$, com a aquisição de imagens digitais analisadas através do aplicativo SIARCS ${ }^{\circledR} 3.0$ (s.d.), e obteve-se as estimativas de funções lineares para $\mathrm{Lv}$ e $\mathrm{AF}$, com base na massa seca de cada componente. Determinaram-se os teores de B disponível em amostras compostas dos substratos preparados no início do experimento, aos 55 e 110 dias, pelo método do extrato saturado 1:1,5 (SONNEVELD e VAN ELDEREn, 1994).

Procedeu-se a análise de variância dos dados para verificação de efeitos de tratamentos, estimativa de modelos polinomiais e cálculo de diferenças mínimas significativas (LSD; $P=0,05$ ) para comparação de médias.

\section{Resultados e Discussões}

Os substratos proporcionaram níveis crescentes de B disponível $\left(0,1 ; 1,0 ; 2,2\right.$ e $4,7 \mathrm{mg} \mathrm{L}^{-1}$, no extrato de saturação), na mesma proporção do ácido bórico aplicado (Tabela 1), decorrente da alta solubilidade da fonte fertilizante. $\mathrm{O}$ valor inicial de $\mathrm{pH}$ do substrato indicou reação ligeiramente ácida, se comparado com a faixa de interpretação de resultados de análises proposta pelo Comitê Europeu de Padronização, entre pH 5,5-6,5 (BAUNGARTEN, 2002). Contudo, mesmo com a adição do ácido bórico, não houve variações significativas nos valores de $\mathrm{pH}$ 4,74,9. A condutividade elétrica (CE) foi relativamente elevada $\left(1,9 \mathrm{dS} \mathrm{m}^{-1}\right)$, provavelmente, em vista da adubação de base utilizada durante a produção na indústria. Valores de CE variando entre $0,1-2,3 \mathrm{dS} \mathrm{m}^{-1}$ foram observados em diferentes substratos (SONNEVELD e VAN ELDEREN, 1994). 
A determinação da condutividade elétrica (CE) de amostras compostas coletadas aos 55 e 110 dias demonstrou redução significativa na concentração dos nutrientes no substrato, avaliada $\left(\mathrm{CE}<0,1 \mathrm{dS} \mathrm{m}^{-1}\right)$. $\mathrm{A} C E$ está diretamente relacionada à quantidade de íons presente no substrato, e sua redução ocorreu em função, principalmente, de perdas por lixiviação e da absorção desses íons pelas plantas. BOAVENTURA et al. (2004) demonstraram correlação entre os valores da CE e o somatório de íons na solução lixiviada através dos recipientes, a qual pode ser usada para estimar as perdas de nutrientes diretamente no viveiro, com apenas um condutivímetro. No referido trabalho, uma unidade de $\mathrm{CE}\left(\mathrm{dS} \mathrm{m}^{-1}\right)$ correspondeu ao somatório total de íons em solução de $10 \mathrm{mmol}_{\mathrm{c}} \mathrm{L}^{-1}$. Os teores de $\mathrm{B}$ foram bastante baixos aos 55 dias $\left(\sim 0,1 \mathrm{mg} \mathrm{L}^{-1}\right)$, havendo discreto aumento aos 110 dias $\left(\sim 0,5 \mathrm{mg} \mathrm{L}^{-1}\right)$, possivelmente devido à mineralização da fração orgânica do substrato, o que coincide com a variaçào de $\mathrm{pH}$ observada entre o início e o fim do período considerado.

Os efeitos dos tratamentos sobre o desenvolvimento das plantas foram observados visualmente já aos 30 dias após o início do experimento. Nas menores doses de B, as folhas dos porta-enxertos apresentaram aparência normal. Contudo, nas doses intermediárias observaram-se sintomas de clorose desenvolvida da borda para o centro do limbo foliar, numa faixa estreita. Na maior dose testada, observaram-se os sintomas caracteristicos da toxidez de B em plantas citrícas, descritos por MatTos Junior et al. (2005), provocados pelo excesso do nutriente, caracterizados por intensa clorose e necrose do tecido, nas margens das folhas, além do retardamento no desenvolvimento dos seedlings.

Tabela 1. Características químicas de substrato tratado com doses de boro para a produção de porta-enxertos de citros em fase de sementeira

\begin{tabular}{|c|c|c|c|c|c|c|c|}
\hline \multirow{2}{*}{ Característica } & \multicolumn{7}{|c|}{ Dose de $\mathrm{B}, \mathrm{g} \mathrm{m}^{-3}$} \\
\hline & 0 & \multicolumn{2}{|c|}{3} & \multicolumn{2}{|c|}{6} & \multicolumn{2}{|c|}{12} \\
\hline & \multicolumn{7}{|c|}{ Inicial } \\
\hline $\mathrm{pH}$ & $4,7^{0,1 *}$ & 4,9 & 0,1 & 4,7 & 0,1 & 4,9 & 0,1 \\
\hline $\mathrm{CE}, \mathrm{dS} \mathrm{m}^{-1}$ & $1,9 \quad 0,2$ & 1,5 & 0,1 & 2,0 & 0,1 & 1,7 & 0,1 \\
\hline \multirow[t]{2}{*}{$\mathrm{B}, \mathrm{mg} \mathrm{L}^{-1}$} & $0,1<0,1$ & 1,0 & $<0,1$ & 2,2 & 0,2 & 4,7 & 0,3 \\
\hline & \multicolumn{7}{|c|}{55 dias após transplante } \\
\hline $\mathrm{pH}$ & $5,9 \quad 0,1$ & 6,1 & 0,1 & 5,9 & 0,1 & 6,4 & 0,1 \\
\hline $\mathrm{CE}, \mathrm{dS} \mathrm{m}^{-1}$ & $0,1<0,1$ & 0,1 & $<0,1$ & 0,1 & $<0,1$ & 0,1 & $<0,1$ \\
\hline \multirow[t]{2}{*}{$\mathrm{B}, \mathrm{mg} \mathrm{L}^{-1}$} & $<0,1^{<0,1}$ & 0,1 & $<0,1$ & 0,1 & $<0,1$ & 0,1 & $<0,1$ \\
\hline & \multicolumn{7}{|c|}{110 dias após transplante } \\
\hline $\mathrm{pH}$ & $5,8 \quad 0,1$ & 6,3 & 0,2 & 6,1 & 0,1 & 6,6 & 0,1 \\
\hline $\mathrm{CE}, \mathrm{dS} \mathrm{m}^{-1}$ & $0,1<0,1$ & 0,1 & $<0,1$ & 0,1 & $<0,1$ & 0,1 & $<0,1$ \\
\hline $\mathrm{B}, \mathrm{mg} \mathrm{L}^{-1}$ & $0,4 \quad 0,1$ & 0,5 & 0,1 & 0,5 & $<0,1$ & 0,5 & 0,1 \\
\hline
\end{tabular}

* Desvio-padrão da media $(n=3)$.

Em trabalhos na literatura constam haver variações na concentração de $B$ nas folhas das plantas cítricas, de acordo com a variedade do portaenxerto (BoARETTO, 2008; PAPADAKIS et al., 2004; TAylor e Dimsey, 1993; Mourão Filho, 1989; Wutscher, 1989; Lima et al. 1980; Cooper et al., 1952; EATON e BLAIR, 1935). Entretanto, essas avaliações não foram realizadas com seedlings em condições de ambiete protegido. Na maior dose de B do experimento, observou-se no citrumelo 'Swingle' folhas com clorose, porém sem sofrer necrose da borda, o que sugere haver uma resposta diferenciada entre as variedades estudadas. WUTSCHER (1989) classificou a tangerina 'Cleópatra', a lima da 'Pérsia', o 'Trifoliata' e o pomelo como variedades que induzem a altas concentrações de B nas folhas de plantas neles enxertadas, enquanto a Severinia buxifolia, o 'Alemow', a laranja 'Azeda' e o citrange 'Carrizo' como porta-enxertos que induzem respectivamente a baixos teores. Como o citrumelo 'Swingle' é originado de um cruzamento entre pomelo 'Duncan' e trifoliata (Pompeu Junior., 2005), é provável que este portaenxerto tolere maiores concentrações de B nas folhas, sem expressar sintomas de toxidez. 
O desenvolvimento das plantas no telado foi satisfatório, atingindo altura superior a $10 \mathrm{~cm}$ aos 110 dias após o transplante. Decarlos Neto et al. (2002), em estudo com diversos porta-enxertos, verificaram que os limoeiros 'Cravo' e 'Volkameriano' foram os porta-enxertos com o maior crescimento, atingindo altura média de $11 \mathrm{~cm}$ aos 120 dias após a semeadura.

As doses de B adicionadas ao substrato promoveram efeitos negativos sobre o acúmulo da massa seca dos porta-enxertos aos 55 e 110 dias (Figura 1A e 1B). No primeiro período, a toxidez de $B$ foi mais pronunciada se comparado à última avaliação (110 dias), o que se correlaciona com os níveis do nutriente extraídos do substrato amostrado nos mesmos intervalos, e que demonstraram o baixo efeito residual do ácido bórico. Aos 55 dias, verificouse que a redução da produção de massa seca do porta-enxeto de 'Swingle' foi de $27 \%$ com o aumento das doses de $\mathrm{B}$ no substrato de 0 para $12 \mathrm{~g} \mathrm{~m}^{-3}$. Da mesma forma, a redução da produção de massa seca do limão 'Cravo' foi de 44\% (Figura 1A). Boaretto (2006) verificou que laranjeiras 'Valência' enxertadas em citrumelo 'Swingle' acumularam em média $10 \mathrm{mg} \mathrm{kg}^{-1}$ de $\mathrm{B}$ a mais que as plantas enxertadas em limoeiro 'Cravo'.

A avaliação realizada aos 110 dias demonstrou maior crescimento do limão 'Cravo' no substrato que não recebeu a aplicação do B, contudo, não houve diferenças entre os porta-enxertos e os tratamentos com 3, 6 e $12 \mathrm{~g} \mathrm{~m}^{-3}$ de B (Figura 1B), constatando-se que o prejuízo inicial causado às plantas proporcionou reflexos negativos até o fim do ciclo de desenvolvimento na sementeira, com um decréscimo médio de aproximadamente $25 \%$ da produção de massa seca para ambas as variedades.

A razão entre a área foliar e o crescimento das raízes varia entre as diferentes espécies vegetais, principalmente, durante o desenvolvimento da planta e devido à influência de fatores ambientais. Entretanto, é possível traçar estreita correlação entre a produção de massa seca das raízes e das folhas (MARSCHNER, 1995). No desenvolvimento da parte aérea (área foliar = AF) dos porta-enxertos de citros estudados houve correlação significativa com o crescimento das raízes (densidade de comprimento $=\mathrm{Lv}) \quad\left(0,60 \leq \mathrm{R}^{2} \leq 0,99\right.$; Figura 2). A correlação entre as variáveis permitiu estimar que ocorreu aumento de AF de aproximadamente $4,5 \mathrm{~cm}^{2}$ para cada unidade de incremento da densidade de raízes. O crescimento das plantas foi proporcional ao índice de área foliar fotossinteticamente ativa. Assim, eventos que promovam prejuízos ao desenvolimento das raízes, limitará seriamente a produção do viveiro.
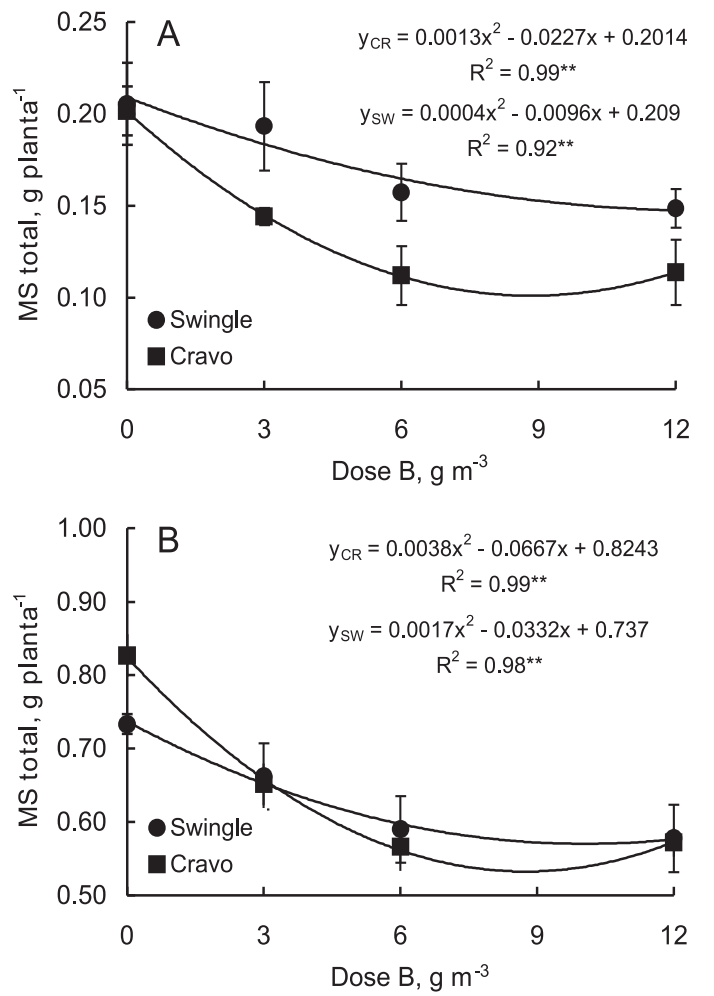

Figura 1. Produção de massa seca (parte aérea + raízes) de porta-enxertos de limão 'Cravo' (CR) e citrumelo 'Swingle' (SW) produzidos em fase de sementeira, aos 55 (A) e 110 (B) dias.

A absorção média de macronutrientes pelos dois porta-enxertos para os diferentes tratamentos aos 55 dias, foi, em mg planta ${ }^{-1}: \mathrm{K}=3,6 ; \mathrm{N}=2,5 ; \mathrm{Ca}=1,4 ; \mathrm{Mg}$ $=0,5$; e $\mathrm{P}=0,4$ e de micronutrientes, em ìg planta ${ }^{-1}$ : $\mathrm{Fe}=48,2 ; \mathrm{B}=12,4 ; \mathrm{Mn}=7,7 ; \mathrm{Zn}=8,4 ;$ e $\mathrm{Cu}=1,0$. Estes valores não variaram significativamente entre os tratamentos testados. BoAventura et al. (2004), em mudas de laranja 'Valência' sobre limão 'Cravo' e citrumelo 'Swingle' desenvolvidas em substrato composto de casca de pínus e vermiculita, observaram a mesma proporção na quantidade de nutriente absorvida, com exceção apenas para a quantidade de $\mathrm{N}$ que foi superior a de $\mathrm{K}(\mathrm{N}>\mathrm{K}>\mathrm{Ca}>\mathrm{S}, \mathrm{P}$, e $\mathrm{Mg}$ para os macro e $\mathrm{Fe}>>\mathrm{Mn}, \mathrm{B}, \mathrm{Zn}$ e $\mathrm{Cu}$ para os micronutrientes). Substratos preparados com grande proporção de casca de pínus tendem a ter elevados teores de Fe total, o que explicaria as diferenças de valores estimados entre os micronutrientes. A menor absorção de $\mathrm{N}$ comparada ao K e o alto conteúdo de Fe pôde ter limitado o crescimento das plantas.

Houve aumento proporcional na concentração de $B$ no tecido das plantas e no acúmulo do nutriente, de acordo com os teores iniciais verificados no extrato saturado dos substratos (Tabelas 1 e 2). 


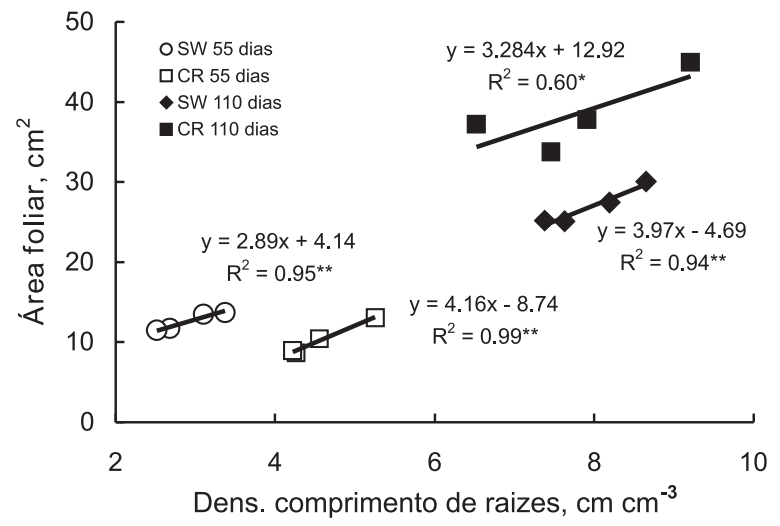

Figura 2. Relação de desenvolvimento da área foliar de porta-enxertos de limão 'Cravo' (CR) e citrumelo 'Swingle' (SW) produzidos em tubetes $\left(0,05 \mathrm{dm}^{-3}\right)$ na fase de sementeira em função da densidade de comprimento de raízes, aos 55 e 110 dias no viveiro.

O teor de B na planta variou de 50 a $110 \mathrm{mg} \mathrm{kg}^{-1}$, não havendo diferenças significativas para os dois porta-enxertos estudados dentro de cada dose testada. A ocorrência de sintomas visuais de fitotoxidade do elemento nas plantas ocorreu com teor de B de cerca de $100 \mathrm{mg} \mathrm{kg}^{-1}$, relativamente inferiores aqueles reportados por MATTOS JúNIOR et al. (1995) para folhas de porta-enxertos com dois a quatro meses de idade em citrovasos (300 $\left.\mathrm{mg} \mathrm{kg}^{-1}\right)$. Esta diferença é explicada provavelmente pela idade das plantas nos dois estudos, entre as fases de sementeira e a formação no viveiro.

Embora não se tenham verificado diferenças nos teores de B na parte aérea das plantas para o citrumelo 'Swingle' e o limão 'Cravo', o acúmulo do B (aproximadamente 10 a $20 \mu$ g planta $^{-1}$ ) diferiu entre as variedades (Tabela 2). Os dados constantes deste estudo sugerem, desta forma, que o citrumelo 'Swingle' é mais tolerante à fitotoxidade de B em sementeira, já que o crescimento (avaliado pela produçao de massa seca; Figura 1A) foi proporcional ao acúmulo de B na planta, que correspondeu a uma diferença de cerca de $45 \%$ entre as variedades no tratamento que recebeu a dose $12 \mathrm{~g} \mathrm{~m}^{-3}$ de B (Tabela $2)$. Essa característica foi também descrita por PAPADAKIs et al. (2004), cujo trabalho demonstrou haver menor tolerância a toxidez de B em tangerina 'Clementina' quando enxertada em laranja 'Azeda' do que em citrumelo 'Swingle'.

Tabela 2. Teor e acúmulo de boro em porta-enxertos de citros produzidos na fase de sementeira no viveiro

\begin{tabular}{|c|c|c|c|c|c|}
\hline \multirow{2}{*}{ Dose de B } & \multirow{2}{*}{ Porta-enxerto } & \multicolumn{2}{|c|}{ Teor B na MS total } & \multicolumn{2}{|c|}{ B acumulado } \\
\hline & & 55 dias & 110 dias & 55 dias & 110 dias \\
\hline \multicolumn{2}{|l|}{$\mathrm{kg} \mathrm{m}^{-3}$} & \multicolumn{2}{|c|}{$\mathrm{mg} \mathrm{kg}^{-1}$} & \multicolumn{2}{|c|}{ mg planta ${ }^{-1}$} \\
\hline \multirow[t]{2}{*}{0} & 'Swingle' & 48 & 29 & 10,0 & 21,0 \\
\hline & 'Cravo' & 48 & 36 & 9,6 & 22,3 \\
\hline \multirow[t]{2}{*}{3} & 'Swingle' & 70 & 44 & 13,5 & 29,4 \\
\hline & 'Cravo' & 89 & 46 & 12,8 & 26,3 \\
\hline \multirow[t]{2}{*}{6} & 'Swingle' & 92 & 26 & 14,4 & 21,2 \\
\hline & 'Cravo' & 95 & 35 & 10,6 & 22,8 \\
\hline \multirow[t]{2}{*}{12} & 'Swingle' & 113 & 35 & 17,0 & 16,4 \\
\hline & 'Cravo' & 104 & 38 & 11,7 & 23,9 \\
\hline \multicolumn{2}{|c|}{$\operatorname{DMS}(P=0,05)$} & 11 & 3 & 2,4 & 1,9 \\
\hline
\end{tabular}

\section{Conclusões}

1. Os sintomas visuais observados para a toxidez de B nas plantas foram caracterísiticos para os dois porta-enxertos e ocorreram quando a concentração do elemento na matéria seca foi maior que $100 \mathrm{mg} \mathrm{kg}^{-1}$.

2. A aplicação de $3 \mathrm{~g} \mathrm{~m}^{-3}$ de B ao substrato causou redução do crescimento dos porta-enxertos, sendo o mesmo acentuado com doses mais elevadas. O maior crescimento e acúmulo de B por porta-enxerto de 'Swingle' comparados ao de 'Cravo' demonstraram a maior tolerância do primeiro à fitotoxidade do nutriente durante o desenvolviemento na sementeira.

\section{Rereferências}

ABREU, C.A.; ABREU, M.F.; RAIJ, B.V.; BATAGLIA, O.C. Extraction of boron from soil by microwave heating for ICPAES determination. Communications in Soil Science and Plant Analysis, New York, v. 25, p. 3321-3333, 1994.

BATAGLIA, O.C.; FURLANI, A.M.C.; TEIXEIRA, J.P.F.; FURLANI, P.R.; GALLO, J.R. Métodos de Análise Química de Plantas. Campinas: IAC. 1983. 48p. (Boletim Técnico 78)

BAUNGARTEN, A. Methods of chemical and physical evaluation of substrates for plants. In: FURLANI, A.M.C.; BATAGLIA, O.C.; ABREU, M.F.; ABREU, C.A.; FURLANI, P.R.; QUAGGIO, J.A.; MINAMI, K. (Coord.) Caracterização, manejo e qualidade de substratos para produção de plantas. 2002. p. 17-28. (Documentos IAC, 70) 
BERNARDI, A.C.C.; CARMELLO, Q.A.C.; CARVALHO, S.A. Macronutrientes em mudas de citros cultivadas em vasos em resposta à adubação NPK. Scientia Agricola, Piracicaba, v .57, p. 761-767, 2000.

BOARETTO, R.M. Boro $\left({ }^{10} \mathrm{~B}\right)$ em laranjeira: absorção e mobilidade. 2006. 120 f. Tese (Doutorado em Ciências) - Centro de Energia Nuclear na Agricultura, Universidade deSão Paulo, Piracicaba, 2006.

BOARETTO, R. M.; QUAGGIO, J.A.; MOURÃO FILHO, F.A.A.; GINE, M.F.; BOARETTO, A.E. Absorption and mobility of boron in young citrus plants. Communications in Soil Science and Plant Analysis, Athens, v. 39, p. 2501-2514, 2008.

BOAVENTURA, P.R.R.; QUAGGIO, J.A.; ABREU, M.F.; BATAGLIA, O.C. Balanço de nutrientes na produção de mudas cítricas cultivadas em substrato. Revista Brasileira de Fruticultura, Jaboticabal, v. 26, n. 2, p.300-305, 2004.

CARVALHO, S.A. Regulamentação atual da Agência de Defesa Agropecuária para produção, estocagem, comércio, transporte e plantio de mudas cítricas no Estado de São paulo. Laranja, Cordeirópolis, v. 23, p.199-239, 2003.

CARVALHO, S.A.; MATTOS JUNIOR, D.; SOUZA, M. Efeitos do $\mathrm{KNO}_{3}$ nos teores de micronutrientes na matéria seca total de porta-enxertos cítricos produzidos em bandejas. Bragantia, Campinas, v. 49, p. 89-94, 2000.

CASTLE, W.S.; ROUSE, R.E. Total mineral nutrient content of Florida Citrus nursery plants. Proceedings of the Florida State Horticultural Society, Ft. Pierce, v.103, p. 42-44, 1990.

CHAPMAN, H.D. The mineral nutrition of citrus. In: REUTHER, L.D. (Ed.) The Citrus Industry. Riverside: Universidade da California. v. 2, p. 127-298, 1958.

COOPER, W.C.; GORTON, B.S.; OLSON, E.O. Ionic accumulation in citrus as influenced by rootstock and scion and concentration of salts and boron in the substrate. Plant Physiology, Rockville, v. 27, p. 191-203, 1952.

DECARLOS NETO, A.; SIQUEIRA, D.L.; PEREIRA, P.R.G.; ALVAREZ, V.H. Crescimento de porta-enxertos de citros em tubetes Influenciados por doses de N. Revista Brasileira de Fruticultura, Jaboticabal, v. 24, p. 199-203, 2002.

EATON, F.M.; BLAIR, G.Y. Accumulation of boron by reciprocally grafted plants. Plant Physiology, Rockville, v. 10, p. 411-424, 1935.

KÄMPF, A.N. Ouso desubstrato em cultivo protegidono agronegócio brasileiro. In: FURLANI, A.M.C.; BATAGLIA, O.C.; ABREU, M.F.; ABREU,C.A.;FURLANI,P.R.;QUAGGIO,J.A.;MINAMI, K. (Coord.). Caracterização, manejo e qualidade de substratos para produção de plantas. Campinas. 2002. p. 1-6. (Doc. IAC, 70)

LIMA, L.A.; MISCHAN, M.M.; SALIBE, A.A. Concentração de boro e enxofre em folhas de laranjeiras doces, determinadas por diferentes porta-enxertos. Revista Brasileira de Fruticultura, Campinas, v.2, n.2, p.54-61, 1980.

MARSCHNER, H. Mineral nutrition of higher plants. 2.ed. San Diego: Academic Press, 1995. p. 313-404.
MATTOS JUNIOR, D.; CARVALHO, S.A.; PEDROSO, F.G. Nitrogen fertilization for Rangpur lime (Citrus limonia (L.) Osb.) seedlings grown under screenhouse environment. Proceedings of the International Congress of Citrus Nurserymen. p. 236-265. 2001.

MATTOS JÚNIOR, D.; QUAGGIO, J.A.; CARVALHO, S.A.; ABREU, M.F. Substratos para a produção de mudas cítricas em recipientes: caracterização da toxicidade de boro. Laranja, Cordeirópolis, v. 16, p. 255-262. 1995.

MATTOS JÚNIOR, D.; BATAGLIA, O.C.; QUAGGIO, J.A. Nutrição dos citros. In: MATTOS JÚNIOR, D.; NEGRI, J.D.; PIO, R.M.; POMPEU JR., J. Citros. 1.ed. Campinas: Instituto Agronômico, 2005. p. 197-219.

MOURÃO FILHO, F.A.A. Efeito de diferente porta-enxertos no vigor e na produtividade das plantas e nas concentrações de macro e micronutriente nas folhas de laranjeira Pera (Citrus sinensis, L., Osbeck). 1989. 189 f. Dissertação (Mestrado em Agronomia) Faculdade de Ciências Agronômicas, UNESP, Botucatu, 1989.

PAPADAKIS, I.E.; DIMASSI, K.N.; BOSABALIDIS, A.M.; THERIOS, I.N.; PATAKAS, A.; GIANNAKOULA, A. Effects of B excess on some physiological and anatomical parameters of 'Navelina' orange plants grafted on two rootstocks. Environmental and Experimental Botany, Oxford, v. 51, p. 247-257, 2004.

POMPEU JUNIOR., J. Porta-enxertos. In: MATTOS JUNIOR, D.; NEGRI, J.D.; PIO, R.M.; POMPEU JR., J. Citros. 1.ed. Campinas: Instituto Agronômico, 2005. p. 61-104.

SCHAFER, G.; SOUZA, P.V.D.; KÖLLER, O.C.; SCHWARZ, S.F. Desenvolvimento vegetativo inicial de porta-enxertos cítricos cultivados em diferentes substratos. Ciência Rural, Santa Maria, v. 36, n.6, 2006.

SIARCS. Sistema integrado para análise de raízes e cobertura do solo. Versão 3.0. São Carlos: EMBRAPA/ CNPDIA. s/d. 30p.

SONNEVELD, C.; VAN ELDEREN, C.W. Chemical analysis of peaty growing media by means of water extraction. Communications in Soil Science and Plant Analysis, New York, v. 5, p. 183-202, 1994.

TAYLOR, B.K.; DIMSEY R.T.; Rootstock and scion effects on the leaf nutrient composition of citrus trees. Australian Journal of Experimental Agriculture, East Melbourne, v. 33, p. 363-371, 1993.

TEÓFILO SOBRINHO, J. Propagação dos citros. In: RODRIGUEZ, O.; VIÉGAS, F.; POMPEU JUNIOR, J.; AMARO, A.A. (Org.). Citricultura brasileira. 2.ed. Campinas: Fundação Cargill, 1991. v.1, p. 281-301.

WUTSCHER, H.K. Alteration of fruit tree nutrition through rootstocks. Hortscience, Alexandria, v. 24, p. 578-584, 1989.

ZANETTI, M.; FERNANDES, C.; CAZETTA, J.O.; CORÁ, J.E.; MATTOS JÚNIOR, D. Características físicas de substratos para produção de mudas cítricas sob telado. Laranja, Cordeirópolis, v. 24, p. 519-530, 2003. 